UCRL-JC-132729

PREPRINT

\title{
Nuclear Relations in South Asia
}

\author{
Neil Joeck
}

This paper was prepared for submittal to the Meeting of the Tokyo Forum of the Hiroshima Peace Institute Hiroshima, Japan

December 18-19, 1998

December 18, 1998

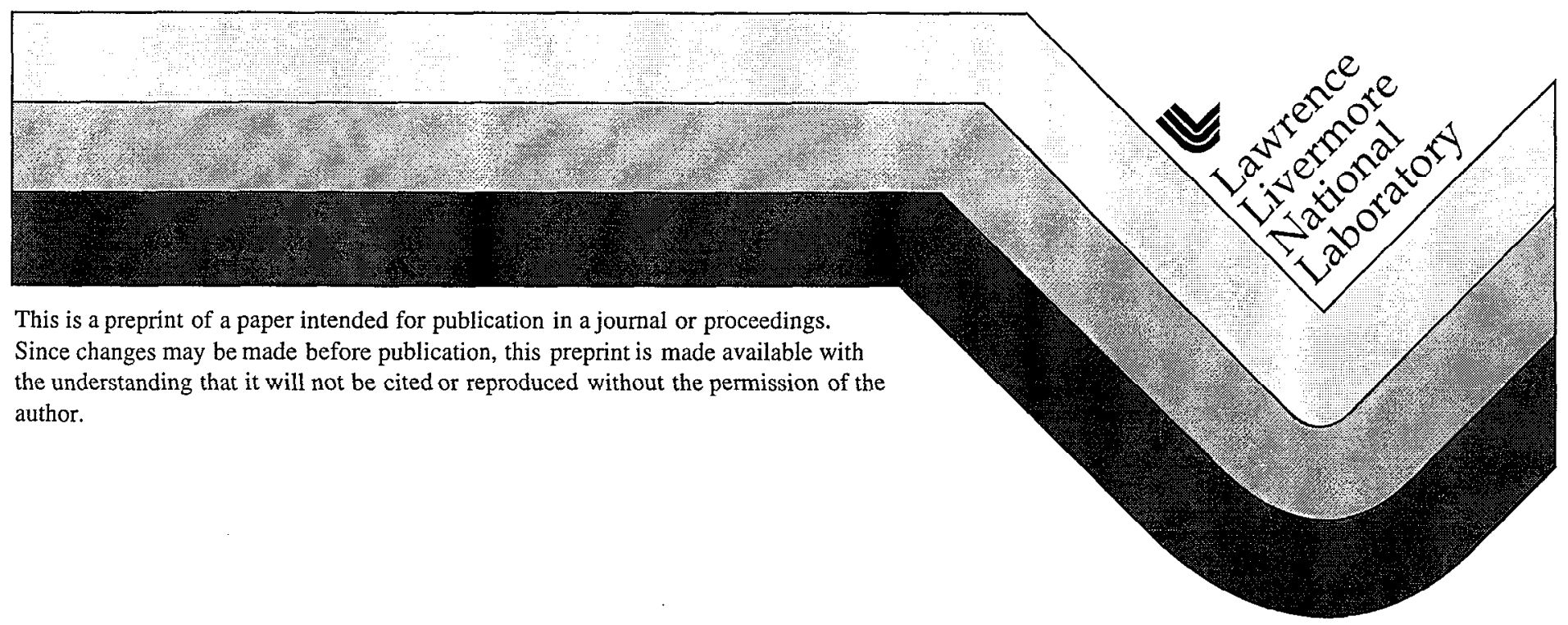




\section{DISCLAIMER}

This document was prepared as an account of work sponsored by an agency of the United States Government. Neither the United States Government nor the University of California nor any of their employees, makes any warranty, express or implied, or assumes any legal liability or responsibility for the accuracy, completeness, or usefulness of any information, apparatus, product, or process

disclosed, or represents that its use would not infringe privately owned rights. Reference herein to any specific commercial product, process, or service by trade name, trademark, manufacturer, or otherwise, does not necessarily constitute or imply its endorsement, recommendation, or favoring by the United States Government or the University of California. The views and opinions of authors expressed herein do not necessarily state or reflect those of the United States Government or the University of California, and shall not be used for advertising or product endorsement purposes. 


\title{
NUCLEAR RELATIONS IN SOUTH ASIA*
}

\author{
Neil Joeck \\ Directorate for Nonproliferation, Arms Control, and International Security \\ Lawrence Livermore National Laboratory \\ University of California
}

This paper was prepared for the meeting of the Tokyo Forum of the Hiroshima Peace Institute,
December $18-19,1998$. The views and materials expressed are the author's and do not
necessarily reflect or state those of the University of California or the United States Government.
Do not cite or quote without written permission of the author.

*This work was performed under the auspices of the U.S. Department of Energy by Lawrence Livermore National Laboratory under contract No. W-7405-Eng-48. 


\section{INTRODUCTION}

The strategic landscape of South Asia changed dramatically in 1998. With the reciprocal testing of nuclear weapons, India and Pakistan emerged from the world of threshold status to an overt posture which has yet to be fully defined. Each claims the status of a nuclear weapon state, yet the contours of that status are unclear. A number of important strategic issues have been raised by these dramatic events. This paper will attempt to examine the implications of this new posture for each country and for the region.

First and foremost, the decisions to test nuclear weapons are a product of each individual state making a sovereign decision about its national security needs. Both have made clear for a number of years that their attitudes toward nuclear weapons-and by default, toward nuclear nonproliferation-will not be directed by outsiders. They have rejected the global norms that oppose the further proliferation of nuclear weapons, embodied in the Treaty on the NonProliferation of Nuclear Weapons (NPT), and that embrace the ultimate elimination of nuclear weapons, captured in Article VI of that treaty. The decisions reached in New Delhi and Islamabad have been questioned by many, but the tests cannot be undone and it now falls on both countries to make further decisions about what strategies will best serve them, and what obligations they must now assume. Issues such as strategic planning, weaponization, deployment, and command and control, which heretofore were relegated to the back burner, may no longer be deferred. 
Beyond the immediate national security issues, however, the tests and the newly claimed status have powerful impacts on immediate neighbors. China must now look on India in a different light, which presumably is precisely what India's leaders desire. Pakistan also sees India in a new light, especially since it considers itself to be the country most threatened by India's nuclear developments. To almost no one's surprise, Islamabad responded promptly by matching India's effort. In turn, of course, India must now look on Pakistan in a different light.

What comes next, however, is at least as important as the nuclear tests. Neither India nor Pakistan has a ready model to examine for guidance about how best to function in a nuclear deterrent relationship. Some analysts look to the US-USSR Cold War confrontation for parallels or examples, but India and Pakistan's geographical proximity, history of direct conflict, and lack of alliance buffers makes their situation quite different. Others argue that India and Pakistan will restrain their competition and do little more than maintain minimum capabilities in order to assure "recessed" or "latent" deterrence. China, watchful and critical of India's actions, is unlikely to make significant changes over the near term, but may have to reevaluate its own strategic posture, which could make it more difficult for India to define what "minimum" means.

Sir Michael Howard said that deterrence rests on a combination of accommodation and reassurance, not on nuclear threats alone. The May 1998 tests certainly made the nuclear threats manifest, and new threats undoubtedly 
will be presented if the two countries demonstrate further technical accomplishments. The elements of reassurance and accommodation must now also be brought to center stage, as they will be at least as important as nuclear threats in ensuring national security.

\section{NATIONAL SECURITY AND STABILITY}

Acquiring an overt nuclear capability may force both India and Pakistan to reexamine a number of issues which might have been delayed or deferred under conditions of nuclear ambiguity. One important issue is the question of how a nuclear capability, regardless of its configuration, meets the country's broad security needs; a more narrow issue is whether or not to weaponize and/or deploy nuclear forces; a third important question involves the need for command and control.

\section{Strategic planning and nuclear capability}

Based on their own pronouncements, India and Pakistan took the step to test nuclear weapons in order to enhance security in what they consider to be an insecure region. In April 1998, India's Defense Minister George Fernandes spoke darkly about the menace from China, while Pakistan's Foreign Minister Gohar Ayub Khan was equally apprehensive in his assessment of India, even before the Bharatiya Janata Party (BJP) began the nuclear test series on May 11. The BJP evidently long ago concluded that an overt nuclear posture was necessary to confront the Chinese threat, and virtually the whole of Pakistan's 
defense structure, from conventional to nuclear capabilities, has been a response to the perceived threat from India. Both have presumably concluded that this overt nuclear posture will enhance security and reduce the likelihood both that war will break out and that they will be targeted with nuclear weapons, if it does.

Indian and Pakistani strategists alike have argued that nuclear weapons have only been used or brandished in the past in situations of nuclear asymmetry-where one state has nuclear weapons but the other does not. Some Indian analysts argue that in situations of nuclear asymmetry; a nuclear armed state may "blackmail" another, i.e. threaten the nonnuclear state without fear of retaliation. By this reasoning, India remained subject to Chinese blackmail, an unstable relationship which needed to be corrected with an overt nuclear posture. Similarly, once India had tested, Pakistan became subject to Indian blackmail, an unstable relationship which also had to be corrected with some kind of response in kind. The nuclear tests in May presumably corrected the asymmetries and instabilities.

These assumptions about the utility of nuclear weapons in redressing security imbalances must not go unchallenged, especially in light of the BJP's initial indication that it would conduct a thorough strategic evaluation of India's defense needs. Rather than evaluating the utility of nuclear weapons as part of India's defense structure, however, the BJP quickly conducted tests which stacked the strategic deck before the Strategic Defence Review (SDR) could be 
conducted. The BJP had also announced that a National Security Council (NSC) would be formed. It was presumably to be the function of this organization to conduct the SDR, and to evaluate what India's strategic needs were. By testing nuclear devices somewhat precipitately, the question of whether or not nuclear weapons were even necessary was made moot. Now it is the task of the NSC to determine how the nuclear devices already tested fit into a strategic plan whose conclusion might otherwise have been that nuclear weapons would ill serve India's needs. The result is that those elements within India who benefit from the nuclear tests-what George Perkovich calls the strategic enclave-have already dictated the terms of the debate.

This should be avoided in the future by ensuring that a variety of points of view are represented in such important decision making. It is not at all clear that an overt policy serves India's strategic needs better than the ambiguous option policy, but it is now too late for argument. The nuclear die is cast; even if India wanted to reverse course, Pakistan has been energized to such an extent that neither side will find it easy to back away from their new status. Whether Western countries recognize India as a nuclear weapons state or not, Pakistan does, and will continue to treat India accordingly regardless of what government holds power in New Delhi.

Pakistanis believe that their strategic calculations are somewhat simpler, at least on the surface. Pakistani historians and political analysts argue that Pakistan's vulnerability was made evident in the 1965 and 1971 wars with India, 
and made it necessary to balance its dependence on outside sources for military assistance and to take steps on its own to counter India's conventional superiority. In 1965, many Pakistanis feel that the U.S., when it cut off military assistance to both India and Pakistan during their August-September war, failed to honor its commitments under the terms of the U.S.-Pakistan defense agreements of the 1950s. Then in 1971, both China and the U.S. stood by and watched as India carved Pakistan into two parts, playing midwife to Bangladesh. This line of argument conveniently overlooks Pakistan's internal dislocations and failed policies, but nonetheless undergirds Pakistan's fairly consistent strategic argument that only an independent nuclear capability will (a) remain under Islamabad's exclusive control and (b) deter India from "finishing the job" it began in 1971. Described in these terms, Pakistan feels that it cannot afford to be seen to be inferior or cowed by Indian behavior. Thus, at every technical turn, Pakistan will attempt to match any Indian development.

Islamabad's external focus, with its preoccupation on the need for nuclear deterrence, overlooks important internal issues which may prove to be more threatening to Pakistani security than any threat posed by India. The events leading up to the 1971 war provide a cautionary tale for Pakistan. It was not grievances with India which either forced or allowed-depending on your point of view-India to exploit Pakistan's weakness. Rather, it was Pakistan's inability to resolve its internal ethnic problems which created conditions of insecurity. 
Pakistan again faces extremely difficult internal challenges: in Karachi with the disenfranchisement of the Muttahid Quami Movement (MQM); in the Punjab with sectarian violence between Sunni and Shi'a; in Azad Kashmir with terrorist forces who may not respond to Islamabad's agenda; and throughout the country with the influence of the Taleban's success next door in Afghanistan, a success many credit Pakistan with enabling. Nuclear weapons will not solve any of those problems. For some, nuclear weapons provide a unifying symbol of Pakistani statehood, but just as the unifying symbol of Islam was by itself insufficient to hold the state together in the 1970-1971 crisis, so too will the symbol of nuclear weapons be insufficient to hold the country together. Vast economic reforms and social programs will provide a much sounder basis for national security than nuclear weapons, whose utility in serving the security needs of Pakistan are connected entirely to events in the past which were essentially domestic in nature. It may well be that Pakistan's nuclear capability will keep India at bay, but they will have no effect on the internal dislocations and failed social policies which again threaten to tear Pakistan asunder.

\section{Weaponization, deployment and stability}

After the Pakistani tests, some scientists were quick to claim that the nuclear devices were already "weaponized" and ready to go on missiles. Less was said in India on this score, but in any case, certain questions now ought to be addressed by both sides. What does weaponization mean? Would the steps involved in weaponization increase or decrease stability? Is deployment 
desirable? What measures will enhance stability? Since the goal in developing nuclear capabilities presumably is to deter rather than to compel, what steps should be taken or avoided to increase stability and to ensure that war never breaks out? Not all of these questions can be answered here, but the need to address them cannot be avoided by strategic planners in New Delhi and Islamabad.

Although the starting point of weaponization is conceptually and physically different from the end point of deployment, a gray area exists where the two merge. It is also clear that a range of command and control mechanisms would have to come into play as a state moved from the basic step of testing a nuclear device toward more technically complicated measures. By way of definition, weaponization can be thought of as the process of developing, testing, and integrating warhead components into a militarily usable weapon system. Deployment can be defined as the process of transferring bombs and/or warheads to military units for storage and rapid mating with delivery systems at military bases.

The first necessary step in weaponization therefore is to design and test a weapon, which both India and Pakistan now claim to have done. The next steps grow increasingly complicated and call for extensive government integration and direction: ensuring that the nuclear devices are accident-proof; designating a delivery vehicle for the tested device; developing the arming, firing, and fusing mechanisms for the weapon; conducting environmental and delivery tests to 
ensure that the weapon system could survive harsh and diverse conditions; developing handling procedures for the weapon components; assigning responsibility for the weapon systems with respect to storage, physical protection, and delivery; and training the responsible personnel. Perhaps in peacetime, but more likely in time of crisis, it might be deemed necessary to deploy the weapons. This might involve mechanically preparing the delivery vehicles, transporting the weapons (or weapon components) to a staging site, final assembling of weapons, mating weapons with delivery vehicles, and delegating the authority to fire.

Based on the foregoing description of this process, it would appear that neither India nor Pakistan has taken steps to weaponize or to deploy their nuclear capabilities. Indeed some analysts argue that these steps need not take place and will not take place, because both sides desire only recessed or latent deterrence-for India against Pakistan and China and for Pakistan against India. Restraint with respect to weaponization and deployment would help to stabilize crises and ensure that nuclear weapons were not used without authorization. Given the lack of any established pattern of high level communication or crisis management in a nuclear environment between and among these states, it might be highly destabilizing to take some of the weaponization steps. The boundary between a "just-in-case" capability and a "ready for use" capability becomes difficult to distinguish as weaponization proceeds. When a country slides into a commitment to prepare weapons for use, it creates enormous uncertainties 
about intentions and may accelerate the pace of competition while undermining the basis for reassurance and accommodation. All sides would benefit from having a very long fuse on their respective nuclear capabilities should a crisis arise or conflict worsen. Avoiding the heightened readiness associated with weaponization would ensure that when tension rises between the two sides, neither is in a position to take sudden action.

This is all the more true with respect to deployment issues. During a crisis, stability is increased if final assembly has not been completed, if lastminute wiring remains undone, and if weapons are not already mated to delivery vehicles. Avoiding deployment would improve safe handling during periods of high tensions, extend the time available for negotiation, reduce the negative influence of inadequate real-time intelligence, and maintain executive control at all times. Public brandishing of the nuclear capabilities places heavy psychological burdens on executives; the best assurance against early or unauthorized use of these capabilities and the best way to reduce stress is therefore to avoid weaponization and deployment.

\section{Command and control}

Beyond showing restraint regarding weaponization and deployment, it is not clear what steps, if any, either state has taken to create command and control mechanisms to reinforce the kind of stability which nonweaponization and nondeployment would create. China's nuclear program has a lengthy history, and includes established command and control mechanisms. Both India 
and Pakistan have organizations whose responsibility, though somewhat unclear, appears to include at least rudimentary command and control. India's Defense Research and Development Organization (DRDO) claimed responsibility for the nuclear tests, and may now be responsible for the stewardship of India's nuclear capability. The Pakistan Atomic Energy Commission (PAEC) and A. Q. Khan Research Laboratories (KRL) jointly claimed credit for Pakistan's tests, but overall supervision of Pakistan's strategic planning (and therefore its nuclear capability) may fall under the Combat Development Directorate (CDD).

An extensive discussion of command and control can be found elsewhere, but it is worth reiterating that an important value in constructing such control modalities is that they send the message both in peacetime and during crises that the central authorities-with whom negotiations to end a crisis or to provide reassurance will be conducted-remain in full control of the nuclear capability. A balance must be struck between preparing for the possibility that deterrence will fail (in which case each state will want to be sure it is able to respond) and maintaining civilian political control over the weapons and their delivery vehicles. If deterrence fails, it is in no state's interest to have the result be the indiscriminate nuclear attacks on the enemy. At the same time, no side wants nuclear decision making to fall under the purview of groups-such as the military or the scientific community-who are either not legitimate authorities or who lack the broader perspective political leadership requires. The issue of command 
and control therefore brings into question the role of the military in both India and Pakistan, as well as the role of their respective scientific communities. India's uniformed services apparently continue to be excluded from strategic decision making and from nuclear issues. The services have recently proposed that a National Command Authority (NCA) be established as a high level command institution, with a National Strategic Nuclear Command (NSNC) reporting to it and comprised of military and technical personnel. Whether this proposal ever is accepted remains to be seen. Pakistan's military appears to already play a central role in developing overall strategy through the CDD. Having now moved from a covert to an overt nuclear status, it may be all the more important that the management of nuclear capabilities not be excessively compartmented, in order to ensure against accidental or unauthorized use. Keeping the military ignorant does not insure against unauthorized use. It only guarantees that if and when nuclear capabilities are handed over to military units-in a crisis, most likely-they will be no better prepared to use the weapons than they would be to avoid using them. Even though the probability of untoward or unexpected action is low, the consequence of failing to prevent it is immeasurably high in a nuclear environment.

Although India appears to have chosen to exclude the military, which may increase risks in a crisis, it does have a centralized and coherent scientific community with important responsibilities. The accountability and direction of that scientific enclave has been questioned by Indian analysts, but not its focus. 
In contrast, Pakistan has evidently involved its military in strategic planning but has a scientific community apparently at odds, which may create similar risks. As noted above, both the PAEC and KRL claimed responsibility for the nuclear tests. Competition between the two institutions, as well as personal animosity, has flared into the open in the past. Some coherence must be imposed by Islamabad on these competing bureaucracies to ensure central control in time of crisis.

\section{DETERRENCE, REASSURANCE, AND ACCOMMODATION}

The decisions by India and Pakistan to test nuclear weapons gave prominence to the role of deterrence in addressing their security needs. The sources of insecurity which drove the nuclear programs may also be susceptible to reassurance and accommodation, however, and should be examined with that in mind.

\section{Sources of insecurity}

The internal cohesion of the Pakistani state, coupled with the continuing dispute over Kashmir, have created important insecurities in the modern history of the subcontinent. Pakistan's historic concerns about India date from the reluctance on the part of many Indian nationalists in 1947 to support the partition of the subcontinent. Although by now it is rare to hear Indians question that historic fact, the rise to power of the BJP alarms many in Pakistan. The BJP's support for Hindu nationalism awakens memories of the turbulent origins of the 
two states and reinforces Pakistanis' sense that India is insensitive to the rights of minorities, Muslims included. On India's side, most analysts argue that the existence of Pakistan and the fact of partition are unquestioned realities, while they point to India's constitutional and statutory defense of ethnic and religious minority rights (especially Muslims and in Kashmir) as ample evidence of India's fundamentally democratic approach.

Memories of the creation of Bangladesh in 1971 also continue to create insecurities for many Pakistanis who fear that India will exploit its internal weakness to further destabilize it. Although most Pakistanis acknowledge that the insurrection and disruption within East Pakistan in the late 1960s and early 1970s was created by Pakistan's own policies, many analysts continue to argue that India took advantage of this internal dislocation and may do so again. Indians respond that Pakistan's internal policies in 1970-71, which sent ten million refugees into India, created threats to India's own delicate internal fabric and were tolerated for many months before action was taken.

In any case, so it is argued in New Delhi, the shoe is by now on the other foot as Pakistan continues to support insurrection within Jammu and Kashmir, where instability and violence have made daily life precarious for a decade. Pakistan insists that the Kashmir dispute can only be resolved when the international community honors the United Nations (UN) resolutions of the 1950s which call for a plebiscite with the state after armed forces have been withdrawn from both the Indian and Pakistani sectors. It is rare that Indians and Pakistanis 
will agree on how to interpret the UN resolutions, and still more rare to find agreement about how to resolve this disputatious issue.

India's concerns with China tend to receive less attention internationally, and indeed within India as well. But it cannot be forgotten that a war was fought in 1962 over border disputes which remain unresolved. Furthermore, conservative Indian strategic analysts are alarmed by a variety of Chinese actions which, as they see it, portend a more aggressive and militant Chinese foreign policy in the future. China's rapidly expanding economy, nuclear weapon modernization effort, naval expansion, attitude toward the Spratly Islands, coziness with Myanmar, arms acquisitions from Russia, willingness to fire lethal missiles over Taiwan, and lack of democratic process all conspire, in the view of some Indians, to make China a serious threat to India's long term interests. Against this background, nuclear weapons presumably offer to redress India's insecurities.

For its part, China professes not to understand Indian concerns, and argues that Sino-Indian border discussions had been proceeding favorably before the BJP assumed power. In any case, China's initial reaction of regret at India's tests appeared to be more connected with the challenge India's tests presented to the NPT and the Comprehensive Test Ban Treaty (CTBT), rather than with the challenge they presented to Chinese security. The Sino-Indian dispute over the McMahon Line which describes their de facto border is an issue 
which, in Beijing's view, is "left over from history and should not result in armed conflict

The point in recounting this history is not to assign blame or to seek vindication, but to recognize that the problems between India and Pakistan and India and China have not been eliminated. The sources of past conflict continue to be part of the South Asian landscape. As noted above, however, that landscape was transformed in 1998 by the overt development of nuclear capabilities. The power of the weaponry each side now brandishes has changed by an order of magnitude, yet the potential sources of conflict remain in place.

Some strategic analysts-K. Subrahmanyam in particular-argue that the creation of this capability now makes conflict less likely, as both sides are deterred from hostile acts that could lead to war. In evidence, Subrahmanyam points to the decision by Pakistan to fire on demonstrators on its own side of the Line of Control (LOC) to prevent their storming into Indian Kashmir and to the reluctance of Indian leaders to authorize military hot pursuit into Pakistan Occupied, or Azad Kashmir. Alternately, analysts like Sumit Ganguly note the problem of the stability-instability paradox, where robust deterrence at the strategic level raises not only the threshold for low-intensity conflict but the risk of unintended war. Local terrorists may assume that national governments are prepared to tolerate low-level conflict in a nuclear environment and may therefore escalate their actions with the result that state-to-state relations are worsened and tensions increased. 
Regardless of which argument one subscribes to, in an environment of overt nuclear competition the stakes of either side being wrong are so great that enormous new burdens are placed on the leadership in India and Pakistan. In an environment where nuclear weapons may be available on both sides, neither New Delhi nor Islamabad can afford to make policy on the assumption that deterrence will always work or that the ceiling on low-intensity conflict will never be breached. The critical feature that must supplement the new nuclear status is a sustained, institutionalized dialogue. A nuclear confrontation is different because neither side can afford to suffer the consequences if the dialogue fails. The other side to deterrence is defense, and in a world where defense is unavailable against nuclear-armed missiles, it is all the more incumbent on national leaders to keep dialogue open. The point is not that India and Pakistan or India and China must agree, but rather that if they choose to forgo dialogue, contentious though it may be, the issues not only will persist but the consequences of their flaring out of control contain enormous dangers for which no side is prepared.

\section{Reassurance and accommodation}

The next steps that must be taken involve providing some form of reassurance and accommodation. A number of confidence building measures have been proposed for some years now, and a few have been adopted, but an air of impatience and frustration tends to greet this issue as India and Pakistan in particular talk past each other. The option of falling back on nuclear threats 
runs serious risks, however, so all sides may want to consider areas where they could perhaps reassure the other about its insecurities, while considering how it might accommodate some of the other's concerns. The most prominent concerns, as noted above, involve Kashmir specifically, border disputes in general, and internal national cohesion.

With respect to Kashmir, it would be reassuring to India if Pakistan were to announce that it opposed terrorism in all its forms and supported a peaceful resolution to the Kashmir dispute. In this vein, Pakistan could announce that it was ceasing all logistical and training support to all Kashmiri forces operating within Azad Kashmir, and take meaningful enforcement steps to back that commitment up. Pakistan's leaders are extremely sensitive to Kashmir issues, and politicians would risk losing votes by appearing to "abandon" Kashmir. At the same time, however, those within Pakistan who feel they can interminably bleed India by supporting cross-border terrorism should not be allowed to dictate the terms of Pakistan's policy on Kashmir. The longer Pakistan's elected leaders allow (or support) such activities, the more will Pakistan's other domestic problems fester. Allowing the practice of cross-border terrorism to dictate policy effectively legitimizes the behavior, and Pakistan simply cannot afford to support a policy in Kashmir which, if applied within Pakistan's borders, would threaten the integrity of the state. The current government's failure to make good on what may have been unwise promises to rename the Northwest Frontier Area Pakhtunkhawa, coupled with the breakdown of its alliance with the MQM in 
Karachi, makes it and Pakistan as a whole all the more vulnerable if the government fails to condemn external interference elsewhere.

For its part, India could accommodate Pakistani concerns, which are directed at the welfare of Kashmiri Muslims. A clear commitment to draw down forces within the state in response to reduced terrorist violence would benefit the weary people who have suffered for a decade. A reduction in chauvinist and confrontational rhetoric would also help, though Pakistan should be reassured by the BJP's decision not to attempt to force through a conservative Hindu social agenda since it has assumed power. In the changed nuclear environment, however, it is not unfair to ask for more, and a clear statement from New Delhi that it respected and supported Pakistan's internal integrity would provide reassurance to Islamabad on this sensitive point.

Regarding border issues, India could reassure China that its nuclear demonstration was not intended as New Delhi's own way of "blackmailing" China by reiterating that it is committed to the peaceful settlement of the border dispute. Although some conservative Indians argue that the border discussions were less productive than advertised, the principle of negotiation ought to be reinforced, especially following Defense Minister George Fernandes' belligerent statements directed at China, Prime Minister A. B. Vajpayee's indiscreet letter citing China as the reason for India's insecurity, and for the nuclear tests themselves. 


\section{Institutional measures}

The types of reassurance suggested above may be offered, but they may also be lost in the noise if not made in an institutionalized form. It could therefore reinforce all parties commitments to the principle of settling their differences by peaceful means if multilateral institutions were established which codified and raised the status of reassuring statements. It might be useful therefore if standing committees were established to discuss Kashmir and border disputes, and if the well established principle of non-interference in the internal affairs of other states were reinforced. Eliminating indiscriminate firing across the LOC, reducing inflammatory propaganda, providing media access, and safeguarding human rights could all be referred to standing committees in order to provide an ongoing forum for the airing of grievances. Further conflict in Kashmir helps neither India nor Pakistan; thus it is incumbent on their political leaders to address the issue of their respective arms developments forthrightly. When the programs were kept under a cloak of ambiguity, tacit measures may have been sufficient to provide reassurance. With them out in the open, tacit measures must be replaced by more focused and unambiguous dialogue.

Beyond the role of reassurance on standing disputes, however, lies the question of how to cope with the overt nuclear confrontation created by the tests. Regardless of what else happens, it is extremely important that India and Pakistan in particular engage in some kind of discussion to maintain political control over the scientific and military accomplishments demonstrated in May. 
(Sino-Indian dialogue should not be ignored, but the nuclear dangers in this relationship still lie somewhere in the future.) After the tests, scientists in both countries may be proud, and military leaders may feel renewed confidence, but political leaders have an increased burden to keep the peace. Peace will not be kept if scientists are encouraged or allowed to develop more and better technical capabilities, while the military's understandable tendency to engage in worstcase thinking has historically produced incomplete analyses of a country's threat environment. Simply stated, political leaders must assert their authority over single-issue bureaucratic actors.

Although joining international regimes is no substitute for direct dialogue, it is salutary that India and Pakistan have decided to join China as signatories to the CTBT. Their declared unilateral moratoria also indicate the seriousness with which both states take their new status. It is clearly not legitimate to argue that India's and Pakistan's nuclear programs are somehow connected with the programs of the five NPT-defined nuclear weapon states (NWS). Islamabad and New Delhi cannot sit back and wait for the NPT NWS to disarm before they make their own firm and binding commitments to restrain themselves.

In addition to announcing before the UN that they would not test any more nuclear weapons and would sign the CTBT, both sides are prepared to engage in good faith negotiations at the Conference on Disarmament on fissile material controls. This too is not a substitute for direct dialogue, but is demonstrative of their mutual seriousness of purpose. It would be even more helpful if they now 
agreed to a moratorium on the production of fissile material while the negotiations proceed. Here they may both pose objections, however, to the extent that they feel that their supplies are inadequate to serve their strategic needs. But again, it is important that the scientific and military enclaves not dictate the terms of the debate even before it is engaged. Both India and Pakistan have said they seek only a minimum deterrent. Toward that end, they should be prepared to accept controls on their own fissile material production in order to avoid each side chasing some impossible answer to the question "how much is enough?" The South African model should be emulated, where tight controls were placed on the scientific community and parts for only seven weapons were actually constructed. India and Pakistan's political leaders can assert their authority over civilian scientists to ensure that debate over the merits of the Fissile Material Cutoff Treaty (FMCT) is not hijacked like the nuclear testing debate.

\section{CONCLUSION}

With their nuclear tests, India and Pakistan have concentrated the world's and their own attention on a key aspect of security. That aspect alone does not guarantee the security of either nation, a point made clear in the USSR and South Africa, where economic and social security were far more important than military security. Having decided to emphasize military security, however, India's and Pakistan's nuclear threats must now be complemented by enhanced 
diplomatic engagement between India and China on one side, and India and Pakistan on another. India can certainly take a leading role in this arena, just as it did with the nuclear test series it began on May 11.

In addition to the broad conclusion that nuclear threats must be accompanied by reassurance and accommodation, a number of specific points also emerge:

- Weaponization of nuclear capabilities would increase crisis instability and should be avoided;

- Deployment of nuclear capabilities would be highly destabilizing under any circumstances;

- Military and scientific research and development must be guided and controlled by political decision makers to avoid isolated bureaucratic enclaves from hijacking decision making;

- In the new nuclear environment, both sides should commit to resolve Kashmir without recourse to arms;

- Nuclear "blackmail" cannot substitute for diplomatic dialogue on contentious territorial and other disputes;

- Nuclear capabilities will not solve domestic ethnic and sectarian conflicts which must be addressed with respect for minority rights;

- Nuclear threats must be accompanied by bilateral discussions across a range of issues, such as:

a) missile research and development; 
b) military to military relations;

c) crisis communication centers;

d) scientific exchange and cooperation.

The world is made less safe with the addition of new nuclear-capable nations. India and Pakistan would argue that, to the extent this is true, their incremental addition pales in significance when compared with the arsenals of the five NPT NWS. But the burden of responsibility is a consequence of technical capability, not of stockpile size or nuclear tests. Countries like Japan, Sweden, Germany, Italy, Argentina, Brazil, Kazakhstan, and Ukraine have every bit as much technical capability as India and Pakistan. They have concluded that they best contribute to their own and to international security by forgoing developing or maintaining that capability. India and Pakistan have drawn different conclusions, however. They now bear the added burden of ensuring that these new capabilities are never used. 